\title{
L'italiano al telefonino: Using SMS to support beginners' language learning 1
}

\author{
CLAIRE KENNEDY AND MIKE LEVY \\ School of Languages and Linguistics, Griffith University \\ Nathan QLD 4111, Australia \\ (email: c.kennedy@griffith.edu.au; michael.levy@griffith.edu.au)
}

\begin{abstract}
This article discusses an experiment in sending regular Short Message Service (SMS) messages to support language learning, and vocabulary learning in particular, at beginners' level in Italian at an Australian university. The approach we took built on the initiatives of Thornton and Houser (2005) and Dias (2002b), and was informed by the results of an earlier trial we had conducted with students at high-intermediate level (Levy \& Kennedy, 2005). In testing the possibilities for using mobile phones for language learning purposes, we were especially interested in investigating the acceptability of a 'push' mode of operation, in which the scheduling of messages is determined by the teachers. While the students appreciated the experience overall, and found the message content often useful or enjoyable, there was a wide range of views on the frequency of messages acceptable. We are therefore planning the further integration of messaging into the course around a flexible arrangement involving options for high or low frequency of pushed messages, as well as messages available on request - in 'pull' mode.
\end{abstract}

Keywords: mobile phone, mobile learning, SMS, Italian, vocabulary, pedagogy, cell phone

\section{Introduction}

Our departure point for experimenting with SMS in the Italian programme at a university in Australia was the expectation that this technology, which is an essential part of our students' everyday lives, could be exploited to support their out-of-class practice. By sending regular messages in and about the language they are studying, we

1. 'Italian on your mobile'. Telefonino is literally 'little telephone'. Many Italians use cellulare and telefonino interchangeably. 
envisaged helping the students take advantage of short periods of time available during the day - such as while on a bus or waiting for a class or appointment. Indeed, there are commercial services that promise success in language learning purely via SMS, on this basis: for example, Morgan Language Solutions at www.smslanguages.com advertises its system of "bite sized lessons" via SMS as a "deceptively simple delivery method, portable and available anywhere and any time" which allows users to "Learn how to speak French or Spanish in 5 minutes per day". We have found no evidence that such an approach on its own brings success, but decided to experiment with using SMS to complement our in-class teaching, with a focus on vocabulary learning in particular.

In this article we first set out the rationale for our work with SMS in Italian learning and describe the approach we have taken in a recent trial with beginners. We then present the results of an evaluation of that approach, concerned with the students' reactions to our use of their mobile phones for teaching purposes - potentially an unwelcome incursion into their personal, social space - and their assessment of the message content. In conclusion we outline the direction we plan to take in future to accommodate the diverse student reactions while integrating the messaging more closely into our courses.

\section{Rationale}

In arguing a practical case for mobile learning in general, ${ }^{2}$ Traxler (2007:8) stressed that it "allows... students to exploit small amounts of time and space for learning...". While he was referring to distance-learning and part-time students, in any field, who need to make use of every available moment, in the case of language learning this advantage of mobile devices can be expected to apply to all students, as regular practice in short bursts is to be encouraged, whether they are on campus or off, and under time pressures or not. In the Australian context, where virtually all university students have mobile phones and use them for text messaging every day (Walsh \&White, 2006), SMS presents itself as a technology that can be exploited to support such practice, free of any "usability issues" (Kukulska-Hulme, 2007).

We perceived the potential of SMS messages particularly for helping language learners build their command of vocabulary. From a practical point of view, vocabulary items can be presented through short definitions and examples that suit the screen dimensions and general handling capabilities of a mobile phone. From a theoretical perspective, we saw the facilities provided by bulk SMS services - to send messages to groups of recipients, schedule them ahead of time and repeat them at intervals - as providing the opportunity to put into practice principles of vocabulary learning that have been well established by research. Key conditions for vocabulary learning identified by Nation (2001) include: repeated encounters with words; thoughtful processing (such as linking them to others); retrieval of meaning in a receptive situation and retrieval for production, especially where this entails effort; and generative use, which involves meeting a known word used in new ways or producing it in new contexts (see also

2. Traxler set this practical case alongside the pedagogical, theoretical one that mobile learning provides access to and equity in learning across different life situations of learners. 
Schmitt \& Schmitt, 1995). We decided to experiment with using SMS to enhance the quantity and quality of our students' exposure to such conditions outside class, by sending regular messages intended to draw the students' attention to words and trigger processing of them in various ways, provide repeated encounters in different contexts of use, and prompt recall for comprehension and production. By devising appropriate content consistent with the course curriculum, and by virtue of the medium - the messages would constitute communication in Italian 'without notice', to be dealt with by the students independently of teachers - we hoped such messages would stimulate students' use of vocabulary learning strategies, particularly determination strategies for discovering the meaning of new words, and memory strategies and cognitive strategies for consolidating command of words, as defined in Schmitt's (1997) schema.

While either SMS or email could be used in theory for sending our messages, email appeared inappropriate in our context for messages of daily or higher frequency. Our students tended to have their mobile phones always on their person and at the ready for receiving text messages, but to check their email only from a PC, in a fixed location and infrequently. Our survey of the first-year Italian students in 2007 showed that only one student out of 91 did not use a mobile phone and, of the rest, $67.8 \%$ had their phone with them "constantly", $27.8 \%$ "most of the day", and only $3.3 \%$ and $1.1 \%$ (four students altogether) "some time every day" or "rarely". They reported on average about four calls and eight SMSs received on a typical weekday, with only two students averaging below one SMS per day. For Internet access and email, however, they nearly all used PCs: only five $(5.55 \%)$ used their mobile phone for email and eight (8.88\%) for accessing Internet sites.

Only SMS therefore offered the possibility of testing the feasibility and acceptability of the 'push' mode of operation we were interested in for vocabulary messages: that is, the use of one-way, unsolicited messages from us to the students, with frequency, timing and any repetition managed by us. Mellow (2005:471) identified a push mode as one of three models for SMS use in mobile learning, along with a 'pull' mode and an 'interactive' one. A pull mode of operation is one in which a student can "order specific information based on a menu of all listed content on a web page or paper handout" to be sent by SMS. An interactive mode of operation is one in which the teachers' messages may be sometimes pushed and sometimes pulled, and in either case the students may respond and then receive feedback on their responses, all by SMS. In our case, it was the students' reactions to the push mode of operation that we particularly sought to investigate, as the value of SMS for us lay in the ability to seek the students' attention at regular intervals, rather than leaving it up to them to decide when to check for messages. To the extent that the students had their mobile phones on, SMSing would allow us to control the time at which they received a message, even if not necessarily the time at which they read it or thought about it. In opting for the push functionality we realized, however, that we would need to cater for, and respond quickly to, any students who found the experiment annoying and preferred to stop receiving the SMSs.

Restricting ourselves to the SMS function, with its 160-character text limit, meant our approach differed considerably from those previously adopted in other applications of mobile phones to language learning. Most of these were implemented in Japan, where a sophisticated network had ensured the mobile phone was young people's preferred vehicle for email communications and Internet access: Dias (2002a:17) reported that 
$96 \%$ of his students had mobile phones, but "only a tiny portion" had PDAs or laptops. Thornton and Houser (2005), working with university students of English in Japan, sent vocabulary messages by email to the students' phones, which allowed them to work with messages of hundreds of words in length. In fact, they described the messages as "minilessons", which defined new words, "used each word in multiple contexts, reviewed previously introduced vocabulary, and incorporated target words in story episodes" (op. cit.: 221). Also in Japan, Kiernan and Aizawa (2004) experimented with the use of mobile phone email by students in carrying out information-gap tasks, where longer messages could again be useful. Other projects incorporated SMSs, but in conjunction with Internet access from mobile phones - to an online vocabulary tutor for students of English in Japan (Stockwell, 2007) and to interactive grammar exercises for ESL students in Canada (Ally, Schafer, Cheung, McGreal \& Tin, 2007).

In addition to vocabulary messages, we decided to include occasional course-related messages of other kinds, drawing on the ideas of Dias (2002b), who sent his students messages about room changes and assignments, or to recommend interesting websites. There is evidence of SMS being effective for general communication between teachers and students, and appreciated by the students, in various disciplines and learning contexts. Fozdar and Kumar (2007:11) reported that students in a Bachelor of Science programme found SMS effective for purposes such as feedback on assignments and notification of important dates and exam results. Horstmanshof (2004:423) argued a stronger case: that the use of texting by a lecturer to keep in contact with her students "supported and encouraged students to persist".

Our first experiment in using SMS was conducted with third-year students, at a highintermediate level of proficiency (Levy \& Kennedy, 2005). The messages were sent at a frequency of two or three per day for a period of five weeks. Most were aimed at drawing the students' attention to vocabulary items encountered in the novel they were studying, and encouraging them to determine or retrieve their meaning or produce them in different contexts. The students generally appreciated the content: they liked both the vocabulary messages and occasional non-vocabulary messages (e.g. about course administration and current events in Italy), and the way later messages prompted recall of vocabulary that had been highlighted in earlier messages, and they called for messages focused on grammatical constructions as well. It was the findings on message scheduling that suggested changes to the approach: a substantial minority of the students found the frequency of messages was too high; and a two-thirds majority found the physical repetition of the same message on two or three different days pointless or even annoying, as they tended to keep the messages and review them in their own time - they were evidently not treating the messages as being for instant consumption and deletion, as we had imagined.

\section{Approach to messaging for beginner-level students}

Following the success with the third-year students - a small group of highly motivated learners who had already invested considerable time and energy in their Italian study - we were keen to test the applicability of SMSing also in our first-year course, for complete beginners. The first-year cohort is always much bigger than that of third year, and made up largely of people who are in their first semester of university studies of any kind. 
In light of the feedback from the third-year students, we decided in the first-year trial to draw attention to grammar as well as vocabulary, and to continue sending other types of messages as well. These were of four kinds: information on Italian life and culture; course announcements (e.g., reminders about deadlines); suggestions regarding TV programmes of interest; and notices inviting students' participation in outside-class activities, for example, the Italian student club's meetings and social events, Italian community celebrations and the opening of a new gelati bar.

The first-year course seeks to develop the students' ability to talk about themselves and other people in daily life, so they are expected to learn vocabulary for talking about studies, work and spare time activities, including sets of words for numbers, days, family members, jobs, physical appearance, personality, clothing, colours, food and drink, sports and hobbies. They also need to master agreement in gender and number for nouns, articles and adjectives, and learn to conjugate verbs in the present tense. In each week's material we identified words, set phrases and/or grammatical points that we thought particularly lent themselves to being reinforced through the messages.

Since this is a beginners' course, our aims go beyond facilitating the students' mastery of basic language elements, to ensuring that their Italian learning process begins on a solid footing in general. This means we seek to cultivate the habit of regular practice, enhance their motivation, and promote their development of personal language learning strategies (Miceli and Visocnik Murray, 2005). We pay particular attention to building the students' ability and confidence in using determination strategies to infer meaning of new vocabulary (Schmitt, 1997) through practice in recognizing cognates and correspondences between Italian and English stems and affixes, as well as exploiting cotextual and contextual clues and background knowledge. We saw the SMSs as potentially serving each of these objectives as well, by making it easy for the students to engage in at least some daily practice; providing input that could trigger their vocabulary learning strategies; promoting their enjoyment of snippets of language and confidence in their ability to understand them; and providing suggestions for other outof-class learning activities such as films on TV and community events.

In devising the content of vocabulary messages we used a variety of formats, in order to present known words in new contexts and new words in familiar contexts, and to encourage use of various types of strategies. Some messages asked a question such as "What's your favourite pizza?"; some set a task (e.g., a "Who is this?" puzzle to solve; a matching, pairing, multiple choice, ranking or odd-one-out activity; some verbs to conjugate or nouns to apply articles to); some made a suggestion such as "Why don't you have a coffee in an Italian bar today?" or "Don't forget to practise these verbs"; and others were focused on presenting new vocabulary items and explanations. Some were intended to make the students think hard, for example, in recalling words or rules, or deciphering a message containing words not previously encountered or used in a new context, and/or to amuse them, arouse their curiosity, or prompt them to take action such as looking something up in the textbook or a dictionary, or raising a question in class or among fellow students.

Some examples can serve to illustrate the ways we sought to trigger retrieval for comprehension or production and promote practice with determination strategies. In the period in which we were working in class on describing people's physical characteristics and personalities, the messages included those shown in Figure A.1 (see Appendix). The 
first of these was a "Who is this?" puzzle, which included some words and expressions introduced in class and some unfamiliar words for guessing. The next re-presented some of the adjectives used in the first and gave the answer to the puzzle, Babbo Natale (Father Christmas), then prompted the students to work out that Natale meant Christmas. The third gave a list of adjectives and invited the student to produce opposites: some of the opposites had been practised a lot in class, while others required greater effort in recall, or the use of determination strategies. The fourth pointed out the frequent correspondence between the suffixes '-ous' in English and '-oso' in Italian, giving several examples. Finally, two messages asked the students to produce adjectives to describe certain famous men and women (in separate messages, to remind them to use masculine forms in one case and feminine in the other); these were individuals to whom several of the '-oso' adjectives might be seen as particularly applicable, as well as those from the list of opposites.

Many messages were in Italian only, while in others either selected words or whole sentences were translated into English in brackets or at the end. Where possible, words that were new in messages, with respect to class work, were recycled in subsequent messages, and then without translation. For example, Non dimenticare (Don't forget) was translated when first used in a quiz reminder, but not when reused later in the message "Non dimenticare di studiare anche i verbi in -ere e -ire..." (Don't forget to study the '-ere' and '-ire' verbs too).

\section{Evaluation}

\subsection{Aims and method}

Through the messaging trial we examined two main aspects of the students' experience: their reactions to our use of SMS to send course-related material to them on a regular basis; and their preferences concerning the type and difficulty level of the message content. We collected data through pre-trial and post-trial questionnaires, both consisting of a mixture of multiple-choice questions and open questions for collecting free-format comments. The first included questions on the students' use of mobile phones in general, any concerns they felt regarding our use of phones for teaching purposes, and their estimate of the number of messages per day it would be appropriate for us to send. The second sought feedback on their experience of the messaging, including preferences for frequency, timing and message content, and on what they did with the messages.

The messaging began in the middle of the semester, after the students had acquired some basic knowledge of Italian. The system used was the bulk, discounted SMS service of one of the major telecommunications providers in Australia, intended for business customers. ${ }^{3}$

The students were invited to opt in to the messaging trial, by either giving us their mobile phone number or letting us know they wished to receive the messages by email

3. The service had a simple online interface which allowed users to: maintain lists of recipients (with names and phone numbers); compose messages and select a recipients' list or enter individual numbers; and either send messages immediately or schedule them for a specific date and time. 
instead. We did not give any instructions as to what to do with the messages, but let them know we would be interested in finding out how they felt about receiving them afterwards. We made it clear they could opt out at any stage, or switch to email, and would not be tested on the message content as such, but only in so far as it reflected the material dealt with in class and homework. In response to occasional student queries we explained we were happy to receive reply SMSs but could not guarantee responding to them, due to time and budget constraints.

We sent a total of 55 messages in seven weeks, at an average frequency of 1.3 per day overall (as Sundays were excluded). We started out using a higher frequency - usually two per day - in order to be sure the students appreciated this as a serious complement to class work, rather than just an optional extra, and because we wished to test where the annoyance threshold really lay, especially as some students initially indicated they would be happy to receive several messages per day. After a snap poll in class in the second week of messaging, which revealed that many students did find two per day too many, we reduced the frequency to one per day, with occasionally none or two. In light of the feedback from the third-year students, we did not do any repeated sending of the same message.

\subsection{Results}

The pre-trial questionnaire was completed by 91 students, in week four of the semester, two weeks before the messaging began. For most of the period of the trial, 76 students were sent the SMSs, while four others were sent the same content by email. ${ }^{4}$ The posttrial questionnaire was completed by 58 students, in week thirteen, the final week of classes. Of these, 52 had completed the pre-trial questionnaire. The discrepancies in numbers were due to students dropping out of or joining the course after week four, or not being in class when a questionnaire was administered. The attendance rate, and perhaps the propensity to complete questionnaires, fell at the end of the semester. Of the students completing the post-trial questionnaire, $86.2 \%$ were women and most (67.2\%) were aged $17-20$, with $24.1 \%$ aged $21-30$ and $8.5 \%$ over 30 . All the students knew the researcher who devised and signed the messages, either as the teacher of one of their classes or as the course convenor.

Receiving SMSs about course content from a teacher was a novel experience for all the students. The pre-trial survey showed that about one third of respondents had used their mobile phones for study-related purposes previously, but such use had been limited to exchanging SMSs with fellow students regarding assessment tasks or using diary functions to remind themselves of deadlines.

4.2.1 What were the students' reactions to receiving regular course-related messages? In examining the students' reactions we were specifically interested in: whether they

4 Of the four students receiving the messages by email, two had requested this from the start (including the lone student who did not have a phone, having previously found it annoying and got rid of it) and the other two switched from SMS to email after two weeks and four weeks of messages respectively. The emails were sent to their official student email addresses, not personal email addresses, and were not always sent at the same time as the SMSs because they could not be scheduled ahead of time as the SMSs sometimes were. 
enjoyed receiving the messages and found them useful; what they did with them; what frequency and timing of messages they considered appropriate; and which, if any, of the concerns they expressed beforehand were borne out.

Overall, the post-trial survey showed that the vast majority of the students had found the experience a positive one. While $84 \%$ said they had enjoyed receiving the messages, most had also found them useful, as they agreed that the messages had helped consolidate their vocabulary $(87.3 \%)$, extend their vocabulary $(82.5 \%)$, and develop their interest in Italian vocabulary $(80.7 \%)$, while a smaller majority felt the messages had helped consolidate their knowledge of grammar (78.6\%).

The students appreciated the variety of message types, with the course reminder messages surprisingly popular. Invited to indicate their preferred type(s) by ticking up to three from a list of six, they ranked vocabulary, grammar and course reminder messages highest (chosen by $81 \%, 77.6 \%$ and $69 \%$ respectively). Smaller numbers chose "information about Italian life and culture" (36.2\%), "notices about what's on SBS or radio programmes" $(27.6 \%)$ and "notices about GUCI events and meetings" $(6.9 \%) .5$ The most common combination was vocabulary, grammar and course reminder messages, chosen by $43 \%$.

There was considerable variation in what the students did with the messages. Most did read them (50\% always, $31 \%$ often, $15.5 \%$ sometimes and $3.4 \%$ - or two students rarely), many saved them for rereading later $(42.9 \%$ did this often and $35.7 \%$ sometimes) and a few volunteered the information in a comment field that they usually wrote them down too. Significantly, most claimed that when a message set a task they tackled it, with $74.1 \%$ usually just thinking of an answer and 6.8\% writing it down. However, the students' propensity to consult dictionaries or textbooks in relation to the messages varied: only $12.1 \%$ did this often, while $20.7 \%$ did so sometimes and $41.4 \%$ only once or twice. And the messages did not trigger much discussion with fellow students: $5.2 \%$ discussed them often, $25.9 \%$ sometimes and $31.0 \%$ once or twice, but $37.9 \%$ never. Comments on the questionnaires suggested that talking about a message was usually prompted by receiving it while students happened to be together.

Dealing with the messages was therefore generally a solitary activity, so it was interesting to discover that many students wanted to reply, especially when a message set a task and students wanted to try out answers on someone. Although we had not encouraged replying, 26 of the 76 students receiving the SMSs sent one or more reply SMSs each, for a total of 63 messages altogether. The great majority (48) of the reply SMSs were responses to the content of our messages - usually answers to the question or task set - and wholly or partly written in Italian. Another fourteen replies, from twelve different people, were instances of students using SMS for course administration matters and miscellaneous queries to do with Italy or Italian, which would normally be sent by email. The last was a case of spur-of-the-moment texting of information typical of the way SMS is used socially by young people: "Ciao Claire. There's an Italian movie on sbs ryt nw $\mathrm{f}$ ne1 was interested cald "im not scared" go queenslanda!! bounannote". ${ }^{6}$

5. SBS is a national public radio and TV broadcaster offering programmes in various languages. GUCI is the students' club, the 'circolo italiano', at our university.

6. A crucial rugby match between Queensland and New South Wales had been televised just prior to the film. Buonanotte means 'good night'. 
We responded occasionally with feedback, and this often triggered a further reply, in acknowledgement or with a correction. Further evidence of the desire to reply and obtain feedback on replies came from four students' comments in the questionnaire. ${ }^{7}$

Some reasons why the students enjoyed the messages and/or considered them useful were expressed in responses to various open questions. The following answers to the final question "Please add any other comments on your experience of this messaging experiment" suggested that the students concerned perceived the benefits in similar terms to those we had aimed at in devising the approach:

- "The messages encouraged me to go over points or vocab seen in class outside my usual study time."

- "It has been a great way to remember things. I usually rewrite messages again for more practice. Thankyou!"

- "It is unique and I found it useful for motivating and reminding myself about Italian."

- "[It] was very helpful, in relation to what was studied, or is going to be studied in class that week. Keeps people on task."

While there were many other positive observations, the claims they made about language-learning benefits or the role of the SMS medium in making the experience enjoyable or beneficial were not specific (e.g. "It's always a good guessing game as to whether it will be from a friend or Italian SMS").

The eight critical observations (out of 24) in response to the final question all concerned the number, frequency and timing of messages, and showed that the main problem for several students was that messages were too frequent for their liking. These observations included "I thought it was generally a good idea although there were a few too many messages" and "too many messages - so I lost interest". Further evidence was provided by the responses to an earlier question inviting specific suggestions regarding the timing and spacing. Of the 17 people who commented, five were happy with the timing and frequency (e.g. "It's good timing, not too much", "It all helps"), but twelve were critical, their observations including: "There were too many messages sent too close together" and "Just not so many in a day".

A more precise picture comes from the answers to the question "How many messages per day do you consider appropriate?", shown in Figure 1. The mean value of the answers (1.5) was higher than the average frequency of messages we had actually sent (1.3). But the proportion of students preferring a considerably lower rate (1 per week: $8.8 \%$; 1 every three days: $7.0 \% ; 1$ every two days: $12.3 \%$ ) suggested a frequency lower than 1 per day might be advisable in future.

Furthermore, it seemed that the majority of students found the messages more intrusive than they had anticipated. Of the 52 students who completed both questionnaires, $67.3 \%$ gave a lower frequency of messages as acceptable in the post-trial

7. The comments were: "We should be able to respond and you could replay back with the spelling mistakes (which most likely it will be) so you know how to write the sentence"; "Can we reply?"; "Can we reply? Good system!"; "I tried answering back, to the questions, but was not able to. Is this available? It would be good to get feedback". 


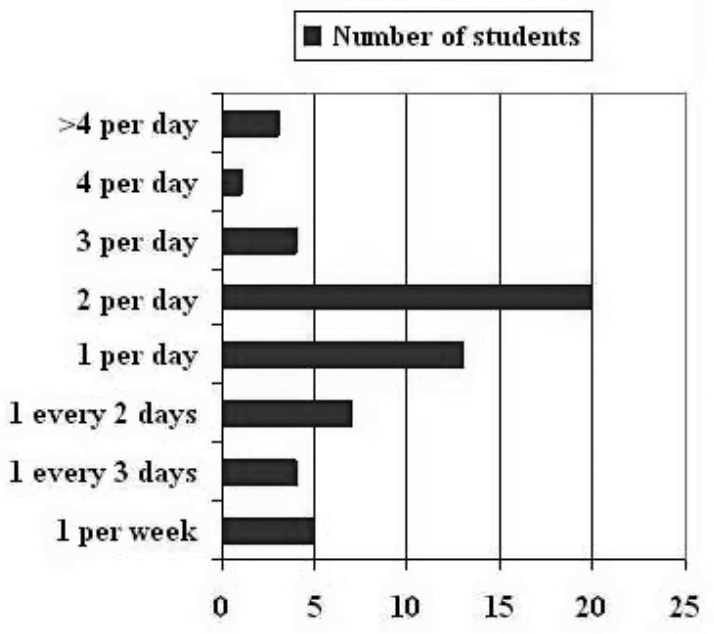

Fig.1. Preferred frequency of messages

questionnaire than the pre-trial questionnaire, while $26.9 \%$ gave the same answer and only $5.8 \%$ gave a higher frequency after the experience than before.

However, it is important to note that there was considerable variation in the number of messages deemed acceptable, and, for as many as were happy with one or fewer per day (29), there were those who welcomed two or more per day (28). ${ }^{8}$ And the minority in favour of a very low rate, of only one or two per week $(15.8 \%)$, was very nearly matched by a minority at the opposite extreme who preferred three or more per day $(14.1 \%)$.

As for the timing of messages, as shown in Figure 2, the students' preferences were quite diverse between $8 \mathrm{am}$ and $7 \mathrm{pm}$, with the most popular times between $10 \mathrm{am}$ and $1 \mathrm{pm}$. But only three specific comments on timing were expressed - "Whenever just not before $10 \mathrm{am}$ ", "Don't send them too early in the morning" and "No messages on the weekend or evening" - suggesting there were no significant problems in this regard for most students.

The few concerns anticipated by students before the trial, other than those of message frequency, were not borne out. Only 21 students $(23.3 \%)$ responded to the question "What concerns, if any, do you have about using your mobile for university work, and specifically us sending you SMSs in relation to Italian?" in the pre-trial questionnaire. Their comments can be grouped into two categories. On one hand were concerns about intrusion, either by our messages themselves - if they were too frequent or arrived at inappropriate times (six comments) - or by junk messages if the students' phone numbers should fall into other hands (five comments). Some concern about the potential intrusiveness of our messages was to be expected - indeed it was a key aspect we intended to investigate - and we made clear to the students that they were free to switch to email, or no messages at all, at any stage. The privacy concerns were also to be

8. One respondent did not answer the question. 


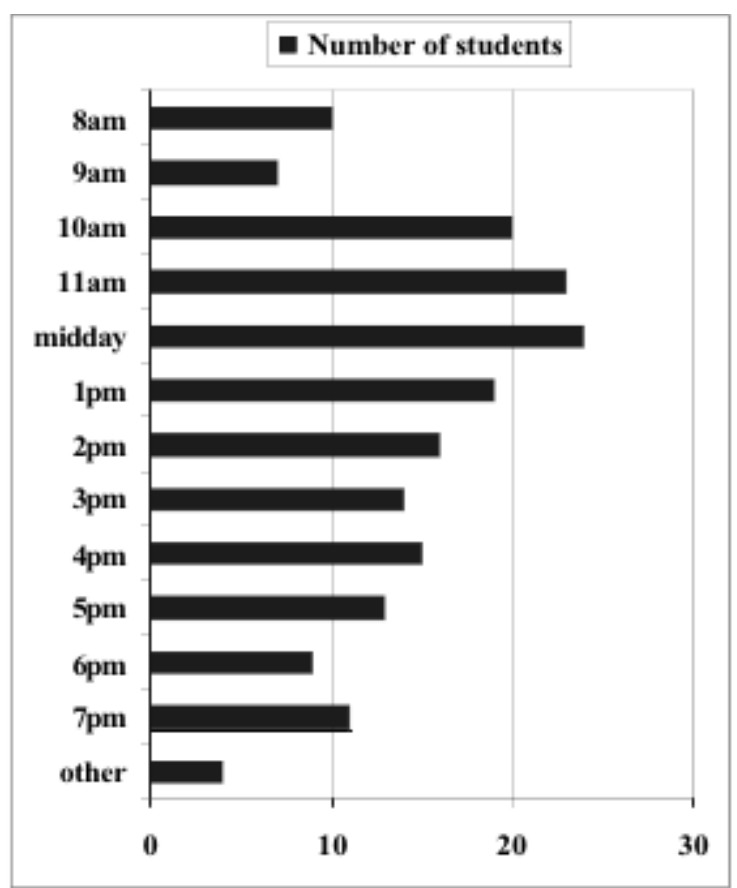

Fig. 2. Preferred times for messages to arrive ${ }^{9}$

expected and we sought to reassure students that the numbers would be kept secret to the extent that this was under our control. In the second category were students' concerns of the opposite kind: about missing something important for their learning if they neglected to have their phone with them and battery charged at all times (nine comments) or failed to understand the messages completely and reply promptly (three comments). We did not expect these concerns to be borne out by the experience of the messaging, given the approach we were taking: we did not encourage replying; and, as there was no assessment linked directly to the messages, and significant course reminders were to be disseminated in the traditional ways as well as by SMS, we did not think any student would be disadvantaged by receiving messages late or not understanding them completely. And in fact, in the post-trial questionnaire responses, the only concern reiterated was that of the potential intrusiveness of frequent messages, and only by a few students. And there were no significant new problems raised. There were concerns about intrusion at particular times, which had not been articulated specifically in the pre-trial questionnaires: "that it will go off in class" and "I do not like receiving more than 1 message a day as it distracts me from my work". In these cases, the remedy is simply to have the phone switched off, of course. There were also comments by two students about the messages filling their inboxes. These did not appear to be offered as complaints, however, but to justify the deletion of the messages, which the students evidently regretted.

9 The students were invited to select up to three options each; some selected more than three. 


\subsubsection{What constituted a good message, for these students?}

In order to gain a picture of which kinds of vocabulary and grammar messages the students had appreciated, we listed a sample of thirteen messages in the post-trial questionnaire and invited them to tick those they considered useful, interesting/enjoyable and/or difficult to understand. We chose the thirteen messages to cover various characteristics such as setting a task, providing explanations, being intended to amuse the students and/or make them think hard.

The students' indications regarding usefulness effectively divided the thirteen messages into two groups, as nine were selected as useful by over $60 \%$ of the students and the other four only by $30 \%$ or less. The nine messages in the first group were all ones that either 'taught' something - by providing explanations or models or imparting new items of vocabulary - or were intended to make the students think hard. Two messages that explicitly gave models for question-and-answer routines received the highest usefulness scores, being selected by $77.6 \%$ and $69 \%$ of students, respectively. Another two with scores of $69 \%$ and $65.5 \%$ invited the students to work hard on both receptive and productive recall with respect to a list of items (with a primary focus on vocabulary and grammar respectively). Of three messages scoring 63.8\%, two imparted new vocabulary (one of them pointing out a recognition strategy too), while the third was intended to exercise the ability to guess on the basis of similarity to English words and co-textual clues. Next in line were two messages focused on recall for comprehension.

Interestingly, the four messages not considered useful by many students included words not previously 'taught' in class but undoubtedly useful - such as perché (why), troppo (too much) and chi (who). It is possible that the students saw these words as simply necessary for the formulation of the task or question, and did not appreciate that introducing them was a useful function of the messages.

As for the interesting/enjoyable category: four of the five messages with the highest scores were those with which we had deliberately set out to amuse the students or arouse their curiosity, so this outcome matched our intentions quite well. The fifth had not been particularly intended to amuse, but what made it interesting or enjoyable was possibly the combination of vocabulary knowledge, determination strategies and general knowledge required to complete the puzzle - one of matching colours to famous people. Notably, the most interesting/enjoyable messages largely coincided with the least useful, in the view of these students.

With respect to the difficulty of messages: one third of the students said they preferred messages they could understand quickly, while only $7.0 \%$ liked messages they found difficult and $59.6 \%$ liked a mixture. We had tried to avoid unnecessary difficulty by giving instructions for tasks largely in English and translating all new Italian words that we thought were not easily guessable. This seemed to have been successful, given that, in response to the question "Do you have difficulty understanding the messages" almost $90 \%$ ticked either "sometimes" or "rarely", in fairly equal numbers, while only six students were at the extremes of "often" or "never" (3.4\% and $6.9 \%$ respectively). Nearly all students appreciated the translations: $19.3 \%$ said they usually needed them, and $73.7 \%$ sometimes. Only three people (5.3\%) said they would have preferred not to have the translations so that they had to work out or look up the meaning for themselves.

The students selected relatively few of the thirteen sample messages in the questionnaire 
as difficult to understand: the highest scoring messages in this category were ticked by only eight (13.8\%), seven (12.1\%) and five (8.6\%) students respectively. In one of these three messages, we had used expressions we intended to be challenging to decipher. In the other two cases, we suspect it was actually the task that was difficult - associating characteristics with famous people - rather than understanding the Italian words.

\subsection{Discussion and implications}

The great majority of students enjoyed the experience overall and found the messages useful, especially vocabulary, grammar and course reminder messages. Clearly, the exact contribution made by the messaging to the students' development of language proficiency cannot be measured, given that this was only one element of their learning environment, in a course with five class contact hours per week. However, if we consider the other three course aims noted above, we can find evidence for a positive contribution in each area. For the cultivation of learning strategies, it is promising that the majority of students said they preferred at least some messages to be ones they had to think about, and that they ranked among the most useful some that required effort in guessing or reasoning from clues. The messages evidently did trigger extra practice on a daily basis for many students, and several showed they were aware this was beneficial, in their questionnaire responses. Finally, occasional reply SMSs - such as "Thanks for your text. I like the programme on Sicily very much" (in Italian) - and comments in the questionnaires on the messages being fun or having a personal tone suggest that the messaging may have helped enhance or sustain motivation for several students.

While the trial established the acceptability for our students of this approach to using SMS in general, a very important aspect of the results is the extent of variation in the students' preferences regarding message frequency. For this cohort, there was no frequency that would have satisfied a substantial majority, especially as many students revised their perception of the acceptable frequency as the messaging period progressed. Catering for the different preferences in future is essential, as the students' responses to this new element of their learning environment must be seen as as a new component of their individual language learning styles, alongside their existing preferences for strategies and techniques, especially in vocabulary learning (Schmitt \& Schmitt, 1995; Oxford, 2003). We plan to adopt a differentiated approach, allowing students to opt into a high-frequency (two or more messages per day) or low-frequency (one message per day) group for 'pushed' messages, with the extra messages being available to the lowfrequency group on a 'pull' basis, from the course Learning Management System (LMS) site or by email. This will also require us to establish criteria for deciding which types of message content to send by SMS to all students and which to send just to the highfrequency group.

The timing preferences also varied but can be easily accommodated. The data suggest that in future most messages should be sent between $10 \mathrm{am}$ and $5 \mathrm{pm}$, with those to the low-frequency group concentrated in the $10 \mathrm{am}-1 \mathrm{pm}$ period, Monday to Friday.

Another finding that merits attention is that, among the sample of messages evaluated, those that the students ranked as most interesting or enjoyable tended to coincide with those scoring lowest on usefulness. Rather than struggle to devise content that is consistently both useful and interesting/enjoyable, we think it best to adopt a policy of 
aiming at one or the other outcome for each message, as it is probably worthwhile to include messages that are intended purely to entertain, for their value in sustaining motivation. Furthermore, if reducing the frequency makes the messaging less intrusive for some students, their perception of the usefulness or enjoyableness of any single message may be greater.

The overall aim of the next phase of our project, incorporating these changes, is closer integration of the messaging into the course. In our view, the benchmark of a successful CALL innovation should be its integration into assessment: such complete integration tests how an innovation fares when it is no longer a novelty and must be taken seriously. This is particularly significant in our case, since the students had not had any similar experience in other courses and the novelty must be assumed to have contributed somewhat to the enjoyment of the trial.

A way to implement such closer integration is suggested by one of the positive findings of the trial: the interest in replying, and obtaining feedback on replies, expressed by a significant proportion of the cohort. The way in which many students took advantage of occasional bursts of time to 'have a go' at replying in Italian indicates it is worth extending the system so as to cater systematically for replies and feedback on them. However, various practical problems present themselves. The cost of replying would be a constraint for some students more than others, creating an inequitable situation. And acknowledging and providing feedback on each individual reply could be extremely time-consuming for teachers, and rarely achievable within the timeframe that usually characterizes SMS exchanges, due to other work commitments and the need to access the online SMS system in order to send messages cheaply.

We therefore plan to create a forum in the course LMS site where students can post replies to the bulk SMSs, and further observations and questions, and the teachers can provide collective feedback. Such a forum will be suited not only to students receiving high-frequency SMSs but those in the low-frequency group and any who opt to simply view messages on the LMS, as each will choose when to participate. With such a system in place, and the requirement for students to participate actively rather than passively, the messaging will become an essential rather than peripheral part of the course. This will permit us to link it to the course assessment through marks for participation in the forum - on the basis of regularity of access and quality of contributions. As a consequence, the devising of appropriate content for the SMSs we send will become even more important, to ensure that the informal, often playful, quality that characterizes most SMS communication in everyday life is not entirely sacrificed to the cause of exploiting its pedagogical potential. At the same time, the forum will be of great benefit in informing teachers and content designers on what works for the students and what does not, helping us to better tailor the content to match their needs and interests.

\section{Conclusion}

Our experiment in using SMS to send regular vocabulary and other course-related messages to beginner-level Italian students has shown it to be a valid new way of communicating with them in and about the language they are studying. We believe this is particularly significant because it means taking advantage of a technology that the 
students already consider an essential part of their daily lives, yet are constantly exhorted to 'switch off!' when engaged in learning activities. The success of our trial in demonstrating the acceptability of messaging for language learning purposes, albeit at a lower frequency than we had initially envisaged, opens the way for further incorporation of messaging into the course and linking it to assessment - an indicator of complete integration that we consider should be the target of any CALL innovation. However, the trial has also highlighted the significance of individual differences in the students' reactions to the messaging, especially regarding the frequency and content. This means that catering for such differences will need to be a priority in further developing our approach. These results should also provide useful insights for other educators and researchers interested in applying a similar approach in the teaching of other languages.

\section{Acknowledgements}

We are grateful to two reviewers for valuable insights and suggestions that led to significant improvements in the paper.

\section{References}

Ally, M., Schafer, S., Cheung, B., McGreal, R. and Tin, T. (2007) Use of mobile learning technology to train ESL adults. In: mlearn Melbourne 2007: Making the Connection: Conference Proceedings (Draft), 5-12.http://www.mlearn2007.org/files/mLearn_2007_Conference_Proceedings.pdf

Dias, J. (2002a) CELL phones in the classroom: Boon or bane? [Part 1] Calling Japan 10(2): 16-22. Dias, J. (2002b) CELL phones in the classroom: Boon or bane? [Part 2] Calling Japan, 10(3):8-14.

Fozdar, B. and Kumar, L. (2007) Mobile learning and student retention. International Review of Research in Open and Distance Learning, 8(2):1-18.

Horstmanshof, L. (2004) Using SMS as a way of providing connection and community for first year students. In: Atkinson, R., McBeath, C., Jonas-Dwyer, D. and Phillips, R. (eds.) Beyond the comfort zone: Proceedings of the 21st ASCILITE Conference, 423-427. http://ascilite.org.au/conferences/perth04/procs/pdf/horstmanshof.pdf

Kiernan, P. and Aizawa, K. (2004) Cell phones in task based learning: Are cell phones useful language learning tools? ReCALL, 16(1):71-84.

Kukulska-Hulme, A. (2007) Mobile usability in educational contexts: What have we learnt? International Review of Research in Open and Distance Learning, 8(2):1-16.

Levy, M. and Kennedy, C. (2005) Learning Italian via mobile SMS. In: Kukulska-Hulme, A. and Traxler, J. (eds.) Mobile Learning: A handbook for educators and trainers. London: Routledge.

Mellow, P. (2005) The media generation: Maximize learning by getting mobile. In: ASCILITE 2005 Conference: Balance, Fidelity, Mobility: maintaining the momentum? Conference Proceedings, http://www.ascilite.org.au/conferences/brisbane05/blogs/proceedings/53_Mellow. pdf

Miceli, T. and Visocnik Murray, S. (2005) Strategy Training: Developing Learning Awareness in a Beginning FL Classroom. In: Bartlett, B., Bryer, F. and Roebuck, D. (eds.) Stimulating the 'Action" as Participants in Participatory Research: Volume 3. Griffith University, School of Cognition, Language and Special Education.

Nation, I. (2001) Learning Vocabulary in Another Language. Cambridge: Cambridge University Press.

Oxford, R. (2003) Language learning styles and strategies: Concepts and relationships. International Review of Applied Linguistics in Language Teaching, 41(4):271-278.

Schmitt, N. (1997) Vocabulary Learning Strategies. In: Schmitt, N. and McCarthy, M. (eds.) Vocabulary: Description, Acquisition and Pedagogy. Cambridge: Cambridge University Press. 
Schmitt, N. and Schmitt, D. (1995) Vocabulary notebooks: theoretical underpinnings and practical suggestions. ELT Journal, 49(2):133-143.

Stockwell, G. (2007) Vocabulary on the Move: Investigating an intelligent mobile phone-based vocabulary tutor. Computer Assisted Language Learning, 20(4):365-383.

Thornton, P. and Houser, C. (2005) Using mobile phones in English education in Japan. Journal of Computer Assisted Learning, 21(3):217-228.

Traxler, J. (2007) Defining, discussing, and evaluating mobile learning: The moving finger writes and having writ... International Review of Research in Open and Distance Learning, 8(2):1-12.

Walsh, S. and White, K. (2006) Ring, ring, why did I make that call? Mobile phone beliefs and behaviour amongst Australian university students. Youth Studies Australia, 25(3):49-57.

\section{Appendix}

Figure A.1 Sequence of vocabulary messages related to describing people

\section{Day Time}

$1 \quad 14.20$

1

17.30

2

09.30

2

3

09.45

4

\section{Message}

Chi e' [Who is it]? E' anziano e molto grasso. Ha i capelli, la barba e i baffi lunghi e bianchi. E' gentile, generoso, paterno, cordiale. E non esiste.

Who is it? He is elderly and very fat. He has long, white hair, beard and moustache. He is kind, generous, fatherly, friendly. And he doesn't exist.

Il personaggio anziano, grasso, gentile, cordiale, paterno, con i capelli bianchi ecc. ecc. e' Babbo Natale. babbo $=$ papa'. Cosa vuol dire Natale?

The old, fat, kind, friendly, fatherly character with white hair etc. etc. is Babbo Natale. babbo=Dad. What does Natale mean?

Can you give an opposite for each of these adjectives? lungo, alto, brutto, grasso, stupido, cattivo, estroverso, noioso, anziano, maleducato, paziente,onesto

Can you ...? long, tall, ugly, fat, stupid, bad, an extrovert, boring, elderly, rude, patient, honest

Note some adjectives ending in -oso similar to English ones in -ous: generoso, geloso, delizioso, ambizioso, ansioso, pericoloso [perilous/dangerous]

Note .... generous, jealous, delicious, ambitious, anxious, dangerous

Think of as many Italian adjectives as you can for each of these: Nelson Mandela, GeorgeWBush, the Dalai Lama, John Howard, Roger Federer, Michael Moore.

Now can you describe these in Italian: Julia Gillard, Amanda Vanstone ('fortunata', to start with, given her new job as ambassador to Rome!), Condoleeza Rice.

[John Howard was Australian Prime Minister at the time and Julia Gillard deputy leader of the opposition] 